\title{
Capillary hemangioma of the orbit: The role of computed tomography
}

\author{
CRISTINA TORRES, D.O \\ JOHN K. KELLY, D.O. \\ FREDERICK B. WATTS, JR., M.D. \\ Detroit, Michigan
}

\begin{abstract}
Capillary hemangiomas of the orbit or eyelid in infants may lead to functional ocular complications. The need to identify and define the extent of such lesions, therefore, is evident. A series of cases from a large metropolitan children's hospital shows a wide spectrum of computed tomographic findings. In this group of cases, most of the tumors were anterior to the globe and did not prevent the development of useful vision.
\end{abstract}

Infantile capillary hemangiomas are common benign tumors that initially tend to grow rapidly and subsequently regress over a period of 1 or more years. Infants with capillary or "strawberry" hemangiomas of the eyelids or orbits are at high risk for developing functional ocular problems secondary to the tumor. These problems may persist long after the tumor has resolved. Therefore, it is important to be able to identify and define the extent of these lesions.

Computed tomography (CT) has had a major impact on the evaluation of diseases of the orbit. By defining the location and extent of the tumor, CT advances the information available for treatment planning. The purpose of this study is to describe the spectrum of CT findings in a series of infantile hemangiomas and to evaluate the role of $\mathrm{CT}$ in diagnosis and management.

\section{Methods}

Nine cases of capillary hemangioma were evaluated at Children's Hospital of Michigan within 9 months after acquisition of the CT scanner. Physicians' office records and hospital records were ana- lyzed for clinical data.

Scanning was performed using a GE 9800 scanner with a 2 -second scanning time. Contiguous (nonoverlapping), 3-mm. sections were obtained. The average number of axial views was between 10 and 11 , and, if direct coronal sections were obtained, the average number was 11 to 14 sections. Hypaque 60 was given by means of a bolus technique of $3 \mathrm{cc} . \mathrm{kg}$. After informed consent, each patient was sedated with intramuscular Nembutal (5 $\mathrm{mg} . \mathrm{kg}$. for patients over $15 \mathrm{~kg}$. in weight and $6 \mathrm{mg}$./ $\mathrm{kg}$. for patients less than $15 \mathrm{~kg}$.).

The field of view was increased prior to filming the orbits by using a target factor of 16 .

\section{Results}

Clinical information was complete in 6 of the 9 cases, as seen in Table 1. There is a female predominance. Most of the capillary hemangiomas presented within the first 6 weeks of life. Four were treated with direct injection of steroid, with resultant regression. One recurred when steroid therapy was discontinued. This lesion, which extended to the cavernous sinus, was the most extensive. Three patients had clinical proptosis (cases 2, 6 , and 9). The same patients had some residual visual or extraocular muscle impairment at the time of this study. Most of the hemangiomas were smaller, however, and caused no visual or functional deficit.

Abnormalities were evident on CT for all 9 patients (Table 2). The spectrum is variable (Figs. 1-7). We did not discover a predilection for the medial or lateral aspect of the orbit; most of the tumors were anterior to the globe. One patient (case 5) presented with only preseptal involvement. Several (cases $1-4,6,8$, and 9) had preseptal plus extraconal in- 


\begin{tabular}{|c|c|c|c|c|c|c|}
\hline Case & Age (mo.) & Sex & Vision & Extraocular muscles & Proptosis & Comments \\
\hline 1 & 1 & $\mathrm{~F}$ & $\begin{array}{l}\text { Normal with a } \\
\text { right eye patch }\end{array}$ & Normal & None & $\begin{array}{l}\text { Initially on right brow; } \\
\text { spread to involve right } \\
\text { lids and cheek. Injection } \\
\text { of the mass with steroids }\end{array}$ \\
\hline 2 & 10 & $\mathrm{~F}$ & $\begin{array}{l}\text { Right difficult } \\
\text { refraction; } \\
\text { obstruction of } \\
\text { visual axis }\end{array}$ & $\begin{array}{l}\text { Right lateral } \\
\text { rectus involved }\end{array}$ & Some & $\begin{array}{l}\text { First noticed at } 5 \text { weeks of } \\
\text { age. Injection to mass }\end{array}$ \\
\hline 3 & 36 & M & & & & No treatment \\
\hline 4 & 3 & $\mathrm{~F}$ & Normal & Normal & None & $\begin{array}{l}\text { Soft-tissue abnormality me- } \\
\text { dial to the right ocular } \\
\text { globe at } 6 \text { weeks. No } \\
\text { treatment. }\end{array}$ \\
\hline 5 & 9 & $\mathrm{~F}$ & & & & No treatment \\
\hline 6 & 5 & $\mathrm{~F}$ & $\begin{array}{l}\text { Left amblyopia; } \\
\text { right normal }\end{array}$ & $\begin{array}{l}\text { Abduction and } \\
\text { depression }\end{array}$ & Minimal & $\begin{array}{l}\text { Grew rapidly and at } 5 \text { weeks } \\
\text { involved left side of face } \\
\text { and nose, and upper and } \\
\text { lower eyelid. Extended } \\
\text { to left upper lip. Steroid } \\
\text { injection and radiation } \\
\text { therapy. }\end{array}$ \\
\hline 7 & 8 & M & Normal & Normal & None & $\begin{array}{l}1 \text { month at presentation } \\
\text { with crying or lying } \\
\text { down. }\end{array}$ \\
\hline 8 & 3 & F & & & & No clinical data available. \\
\hline 9 & 9 & $\mathrm{~F}$ & Normal & $\begin{array}{l}\text { Divergent strabismus; } \\
\text { slight restriction } \\
\text { to adduction }\end{array}$ & Yes & $\begin{array}{l}\text { First presented at } 6 \text { weeks. } \\
\text { Oral steroids admin- } \\
\text { istered elsewhere de- } \\
\text { creased size of } \\
\text { hemangioma on face and } \\
\text { lid. Steroid injection de- } \\
\text { creased lid size. }\end{array}$ \\
\hline
\end{tabular}

\begin{tabular}{|c|c|c|c|c|c|c|c|}
\hline Case & Intraconal & Extraconal & Preseptal & Scleral & Intracranial & Optic Nerve & Other \\
\hline 1 & + & + & + & + & - & $\begin{array}{l}+ \\
+\end{array}$ & $\begin{array}{l}\text { Right superior orbit } \\
\text { fissure identified }\end{array}$ \\
\hline 2 & + & + & + & - & $\begin{array}{l}\text { Cavernous } \\
\text { sinus }\end{array}$ & + & $\begin{array}{l}\text { Superior orbital } \\
\text { vein present } \\
\text { superficially }\end{array}$ \\
\hline 3 & - & $\begin{array}{l}+ \\
-\end{array}$ & + & + & - & - & \\
\hline 4 & - & + & + & + & - & - & \\
\hline 5 & - & - & + & - & - & - & \\
\hline 6 & + & + & + & - & - & + & Fnonhthalmos \\
\hline 7 & - & - & $\begin{array}{l}+ \\
+\end{array}$ & - & - & - & $\begin{array}{l}\text { Enophthalmos } \\
\text { Medial hemangioma }\end{array}$ \\
\hline 8 & - & $\begin{array}{l}+ \\
+\end{array}$ & $\begin{array}{l}+ \\
+\end{array}$ & & - & & Left exophthalmos \\
\hline 9 & $\stackrel{+}{-}$ & & & & & & \\
\hline
\end{tabular}

volvement (Figs. 1-5, 7). Only one patient (case 2) had extension of the mass throughout the orbit and back to the cavernous sinus (Fig. 2).

Hemangiomas have a higher attenuation than surrounding soft tissue and significant contrast enhancement, as can be seen especially in Figures 3, 4,6 , and 7 . The contour is irregular and the mass may protrude into the periorbital fat. If intraconal involvement is present, the typical low-density (dark) intraorbital fat behind the bulb exhibits much higher density before and after contrast enhancement. Because the tumor is noninvasive, the globe and bone are not involved directly; however, this series included 2 cases of unilateral proptosis and 1 of enophthalmos (case 7). The orbit was enlarged in the 3 most extensive cases. The optic nerve appears enveloped in 3 cases (Figs. 1, 2, and 5 ). The extraocular muscles were involved in cases 2, 6, and 9 (Figs. 2, 5, and 7).

\section{Discussion}

Capillary hemangiomas are the most common vascular lesions of the orbit or lid. There is female predominance with a $3: 2$ female-male ratio in one 

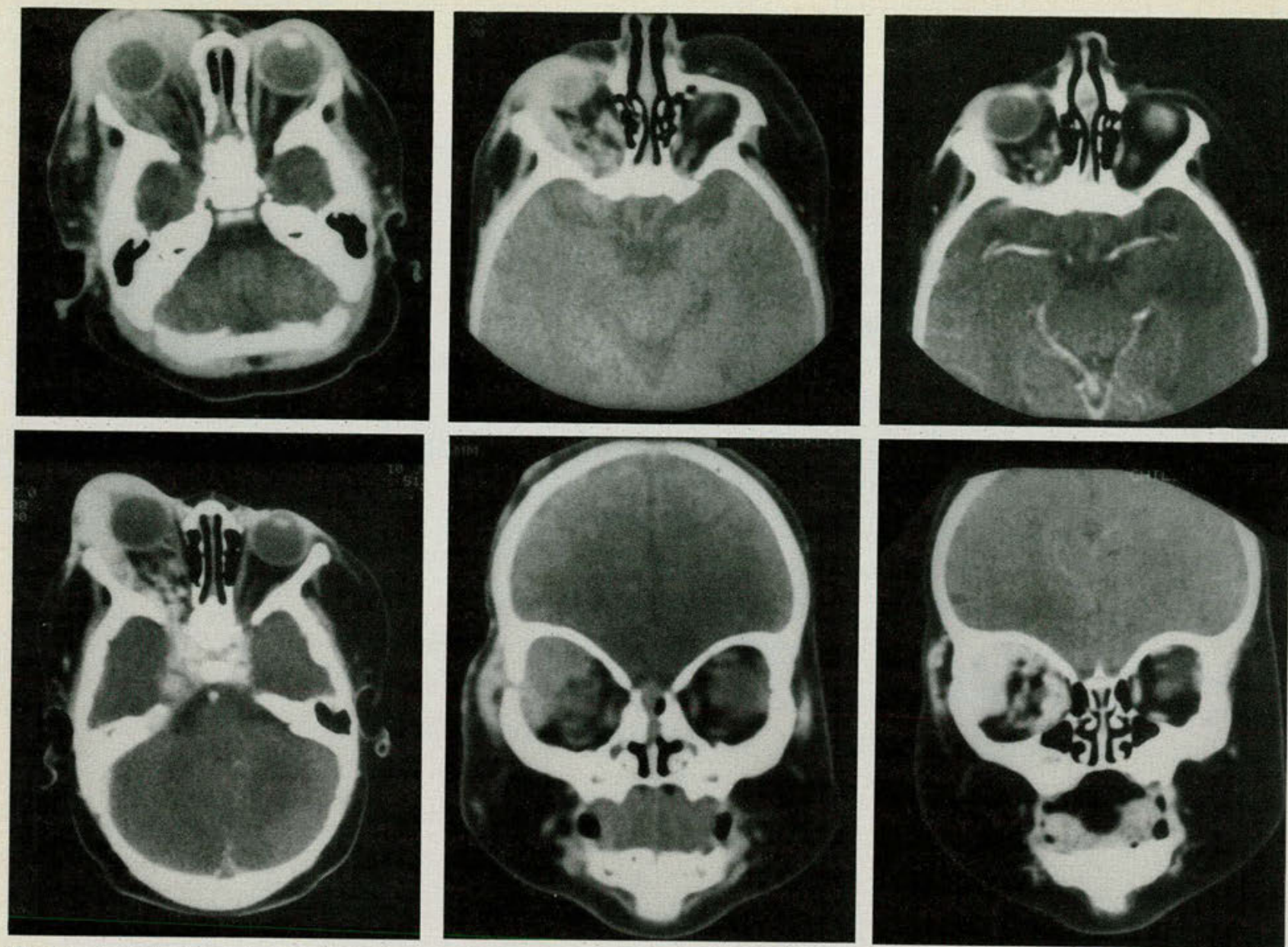

Fig. 1 (upper left).(Case 1). Large preseptal mass anterior to the right orbit and extending posteriorly bilaterally. A small portion of this hemangioma is intraconal. The sclera and nerve are involved. Figs. $2 \mathrm{~A} .-2 \mathrm{E}$. (Row 1, center and right, Row 2). (Case 2 ) $2 A, A$ right preseptal mass, cut low through the orbits without enhancement. It extends along the lateral extraconal orbit. Expansion of the orbit is present. $2 B$, With contrast enhancement, the right preseptal capillary hemangioma is shown extending laterally. $2 C$, The same highdensity mass extends through the posterior orbital fissure into the cavernous sinus. Intraconal involvement and orbital expansion are present. The nerve and muscles are enveloped. $2 D$ and $E$, Coronal sections through the same lesion, without (left) and with (right)
contrast enhancement.

series of 101 cases involving these structures. ${ }^{1}$ Usually, the mass is noted at birth or in the first 6 months. ${ }^{2}$ The mass which often is colored red or blue, may change size during crying. ${ }^{1,3}$ The lesions typically increase in extent during the first 3 or 4 to 12 months of life, remain quiescent for a while, and then spontaneously resolve. ${ }^{1}$ Complete resolution usually occurs by the age of 7 years. ${ }^{3}$

Rapid growth, however, not only may be cosmetically distressing but also may interfere with vision from pressure on the globe or optic nerve or by sensory deprivation during a critical period for visual development in early life..$^{2,4}$ Complications include functional amblyopia, anisometropia, strabismus, pupillary occlusion, proptosis, optic nerve atrophy, and skin changes. ${ }^{1,2,4,5}$ In the series of cases reported here, useful vision developed in most instances. Associated thrombocytopenia may cause a bleeding diathesis, which can be life threatening (Kasabach-Merritt syndrome). ${ }^{1,6}$ Treatment, if necessary, is generally more effective when carried out early in the natural course of the tumor. ${ }^{4}$

The radiographic evaluation with CT should include contrast enhancement. Soft tissue and bone can be evaluated simultaneously using the newest CT scanners. Plain film tomography does not evaluate soft tissue well, and ultrasonography is unable to define the periorbital structures and bone. ${ }^{7}$ Although a histologic diagnosis is impossible with only CT, the differential diagnosis can be narrowed, because evaluation of size, location, configuration, calcium content, and enhancement will help to differentiate hemangiomas from other possible orbital lesions.

The clinical differential diagnosis of capillary hemangiomas encompasses all orbital conditions that can affect children. These primarily include inflammation, hemorrhage, lymphangioma, neurofibromatosis, and rhabdomyosarcoma. Bone changes are more frequent with malignant tu- 

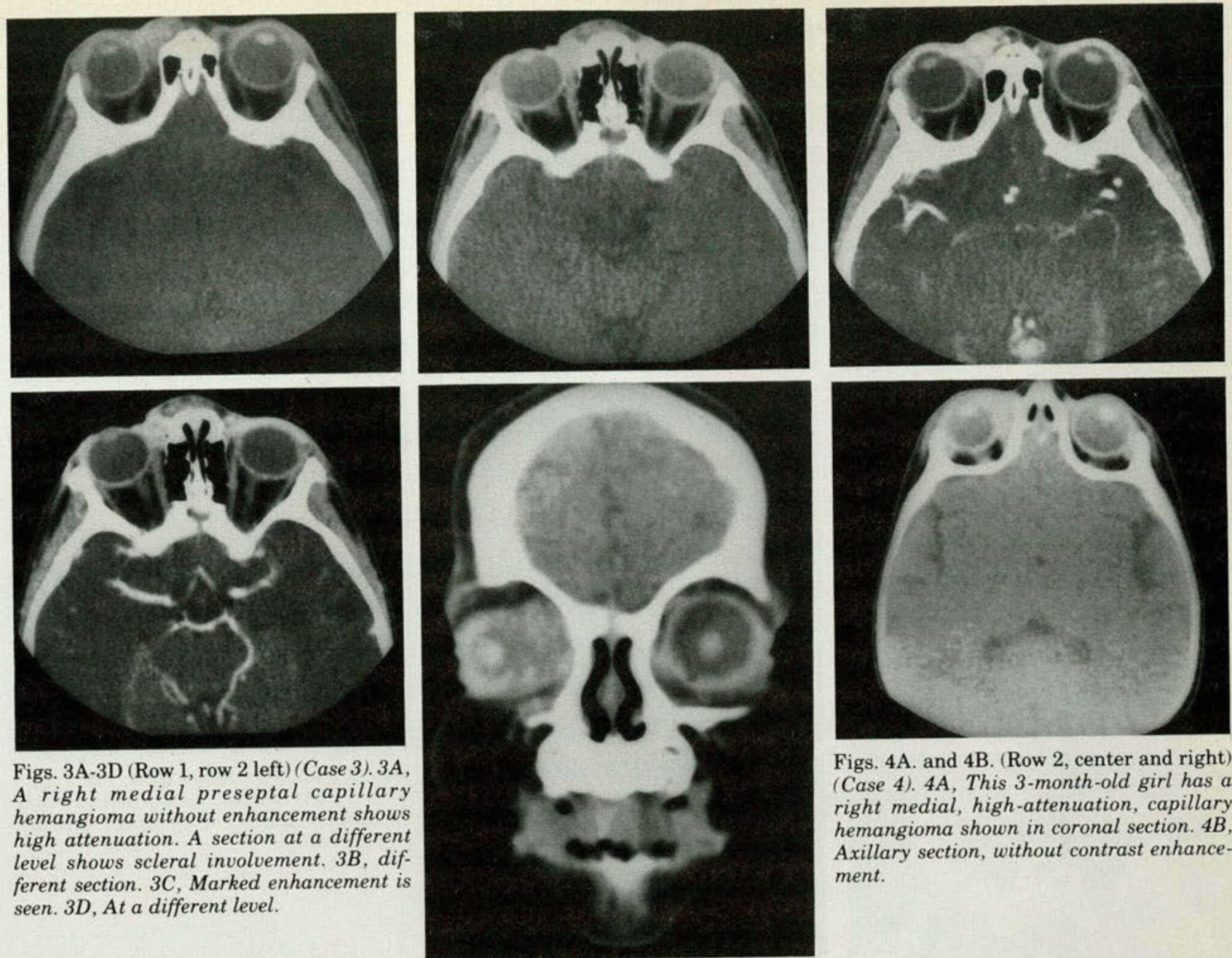

Figs. 4A. and 4B. (Row 2, center and right) (Case 4). 4A, This 3-month-old girl has a right medial, high-attenuation, capillary hemangioma shown in coronal section. $4 B$, Axillary section, without contrast enhancement.

ferent section. $3 C$, Marked enhancement is seen. 3D, At a different level.

mors. ${ }^{8}$ Therefore, rhabdomyosarcoma might be expected to cause bone destruction. Orbital enlargement without erosion has been reported ${ }^{9}$ and was observed in this study. Neurofibromas may be associated with an elevated sphenoid wing or defect in the sphenoid bone. ${ }^{7}$ In cases of hemorrhage or hematoma, bone fracture may be observed. Inflammation may be associated with lack of a well-defined mass. ${ }^{8}$ If tumor is present, however, the superior ophthalmic vein appears displaced and may be compressed. Lymphangiomas show either absence of or minimal heterogeneous contrast enhancement and have irregular, diffuse margins. ${ }^{10}$ None of the tumors mentioned can be expected to regress spontaneously.

Capillary hemangiomas can be differentiated from cavernous hemangiomas. Most cavernous hemangiomas are intraconal. The mean age of onset for cavernous hemangiomas is 48 years. ${ }^{10}$ The total lack of chronologic overlap between capillary and cavernous hemangiomas helps to differentiate these tumors. ${ }^{1}$ Also, I found capillary hemangiomas to be mainly anterior, with some retrobulbar extension. Most cavernous hemangiomas are posterior, superior, and lateral..$^{10}$

Capillary hemangiomas can be expected to be well-delineated, space-occupying lesions with a higher density than the surrounding tissue. Contrast enhancement increases the density uniformly. Differentiation from surrounding structures including the optic nerve is easily visualized. The tumors were usually anterior to the globe in this study. Orbital expansion and proptosis, with extensive involvement of the orbit, are possible.

\section{Comment}

Computed tomography has been very useful in evaluating orbital capillary hemangiomas. Although this sample is small, it includes a wide variety of lesions. No previous paper has shown such a spectrum of computed tomographic findings with orbital capillary hemangiomas. 

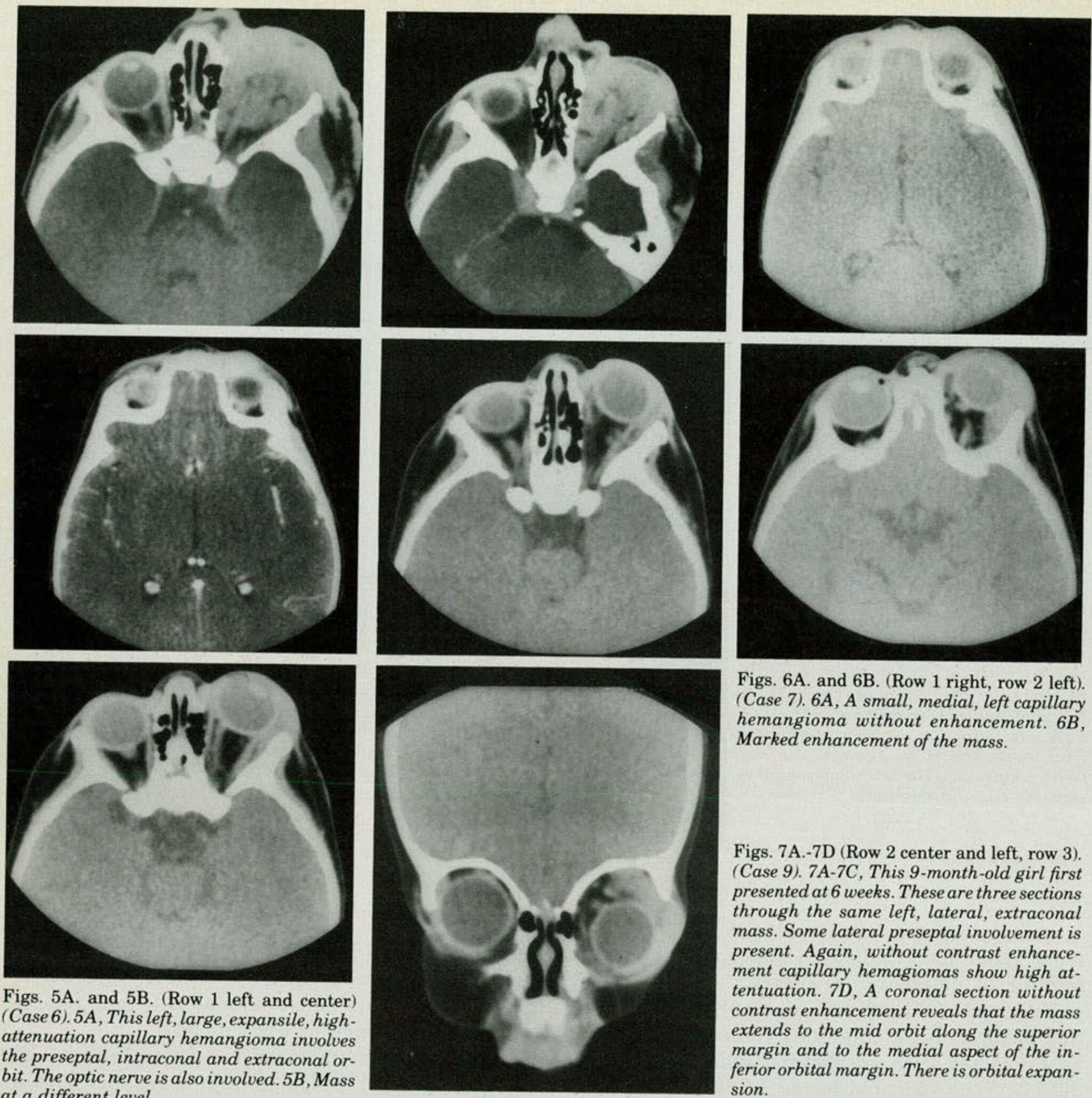

Figs. 6A. and 6B. (Row 1 right, row 2 left). (Case 7). 6A, A small, medial, left capillary hemangioma without enhancement. $6 B$, Marked enhancement of the mass.

Figs. 5A. and 5B. (Row 1 left and center) (Case 6).5A, This left, large, expansile, highattenuation capillary hemangioma involves the preseptal, intraconal and extraconal orbit. The optic nerve is also involved. 5B, Mass at a different level.

ated by computed tomography. Radiology 136:101-11, Jul 80 9. Aron-Rosa, D., Doyon, D., and Dassonville, J.: Angiography in vascular malformations of the orbit. Mod Probl Ophthalmol 14:146-55, 1975 10. Davis, K.R., et al.: CT and ultrasound in the diagnosis of cavernous hemangioma and lymphangioma of the orbit. CT 4:98-104, 1980

At the time this paper was written, Dr. Torres was a resident in diagnostic radiology, Michigan Osteopathic Medical Center, Detroit. The residency trainers were Robert Katz, D.O., and Joseph J. Mittner, D.O. Dr. Torres is now a staff radiologist at Health Alliance Plan, Detroit. Dr. Kelly is a clinical assistant professor or radiology, Wayne State University, Detroit, and a neuroradiolgist on the staff of Harper Hospital, Detroit. Dr. Watts is a clinical associate professor of radiology at Wayne State University, and a pediatric radiologist on the staff of Childrens Pediatric Hospital, Detroit.

Dr. Torres, 1800 Tuxedo Road, Detroit, Michigan 48206. 